\title{
Centros de ReEduCAÇÃo EM MoÇAMbique (1975-1985): MEMÓRIAS, SILÊNCIOS E DISCURSOS JORNALÍSTICOS
}

\author{
Orquídea Ribeiro \& Daniela da Fonseca
}

\begin{abstract}
RESUMO
No período pós-independência, o objetivo da Frelimo era "livrar a sociedade moçambicana de mazelas associadas ao mundo colonial, burguês e capitalista, rumo à construção do Homem Novo, que passava necessariamente por um processo de "reeducação", no interior do qual os indivíduos seriam introduzidos numa nova ordem" (Thomaz, 2008, p. 179). Esta nova ordem implicava "trabalho disciplinado, despojamento material, superação de antigas lealdades (étnicas, religiosas, de classe, de raça, regionais) e comportamento moral inatacável" sinónimo do "ideal de Homem Novo" (Thomaz, 2008, p. 179). Os artigos publicados em jornais moçambicanos da época contrastam com os textos dos media internacionais. Ungulani Ba Ka Khosa apresenta, em Entre as memórias silenciadas (2013), um retrato de Moçambique nos primeiros anos do período pós-independência com a ficção a alertar para a necessidade de desafiar e recuperar as memórias silenciadas dos campos de reeducação instituídos pelos dirigentes da Frelimo para construir/educar um "Homem novo". Ba Ka Khosa (2013) procura desmistificar e exorcizar a história do passado recente com um texto que (re)visita a realidade moçambicana no período pós-independência, que para os reeducandos foi sinónimo de violência, sofrimento e exclusão da história e da memória. Como um dos autores mais provocadores da contemporaneidade moçambicana, Ba Ka Khosa "dilui o passado no presente, a ficção na realidade, fazendo da literatura um vivaz espaço para o debate político" (Gallo, 2013, p. 293). Neste artigo propõe-se analisar a obra de Ungulani Ba Ka Khosa em paralelo com os textos publicados nos meios de comunicação nacionais e internacionais.
\end{abstract}

\section{RE-EDUCATION CENTRES IN MOZAMBIQUE (1975-1985): MEMORIES, SILENCES AND JOURNALISTIC SPEECHES}

\begin{abstract}
In the post-independence period, Frelimo's goal was to "free Mozambican society from damage related to the colonial, bourgeois and capitalist world, towards the creation of a New Mankind that would necessarily go through a process of 're-education', pursuant to which individuals would be inserted into a new order" (Thomaz, 2008, p. 179). This new order implied "disciplined work, material detachment, overcoming old loyalties (ethnic, religious, class, racial, regional) and unassailable moral behaviour" meaning the "ideal of a New Mankind" (Thomaz, 2008, p. 179). Articles published in Mozambican newspapers at the time contrast with international media texts. In Entre as memórias silenciadas [Between silenced memories] (2013), Ungulani $\mathrm{Ba}$ Ka Khosa portrays Mozambique in the first years of post-independence through fiction, alerting to the need for challenging and retrieving the silenced memories of the re-education camps, implemented by Frelimo's leaders, to build/educate a "new Mankind". Ba Ka Khosa (2013) seeks to demystify and exorcise the history of a recent past with a work that (re)visits Mozambican reality in the post-independence period, which, to the re-educated, was synonym of violence,
\end{abstract}


suffering and exclusion from history and memory. As one of the most provocative authors of Mozambican contemporaneity, Ba Ka Khosa "blurs the past with the present, fantasy with reality, transforming literature into a live space for political debate" (Gallo, 2013, p. 293). This paper has the purpose of analysing the work of Ungulani Ba Ka Khosa and, simultaneously, the pieces published in national and international mass media.

\section{KEYWORDS}

Re-education centres; Mozambique; memory; Ungulani Ba Ka Khosa; press

\section{INTRODUÇÃO}

O trabalho que aqui se apresenta tem como principal objetivo a análise da receção dos temas dos campos de reeducação em Moçambique, nos jornais da época (19751985), comparando os conteúdos editados pela imprensa moçambicana e pela imprensa internacional e estabelecendo um paralelo e uma comparação com a obra Entre as memórias silenciadas (2013) de Ungulani Ba Ka Khosa.

No período pós-independência, o objetivo da Frelimo era o de "livrar a sociedade moçambicana de mazelas associadas ao mundo colonial, burguês e capitalista, rumo à construção do Homem Novo, que passaria necessariamente por um processo de "reeducação", no interior do qual os indivíduos seriam introduzidos numa nova ordem" (Thomaz, 2008, p. 179). Esta nova ordem implicava "trabalho disciplinado, despojamento material, superação de antigas lealdades (étnicas, religiosas, de classe, de raça, regionais) e comportamento moral inatacável" sinónimo do "ideal de Homem Novo" (Thomaz, 2008, p. 179).

Após a independência, a Frelimo esforçou-se por implementar um "protocolo utopiano de regeneração social" (Serra citado em Moreira, 2010, p. 112) para criar o "homem novo" com o objetivo de "combater os "reaccionários" e o desvio ideológico, as "estruturas políticas retrógradas", a sabotagem económica, o desemprego, a vagabundagem, o afluxo às cidades, etc. Uma atenção muito particular foi dada à "infiltração", à "detecção" e à "denúncia" dos "elementos infiltrados" (Serra citado em Moreira, 2010, p. 112). Para este "combate" aos desvios sociais, apontados pelo governo da Frelimo, foram criados os centros/campos de reeducação que eram na realidade campos de trabalhos forçados e que integram um capítulo por escrever na história de Moçambique. Para estes lugares de repressão localizados em regiões distantes da capital, principalmente no norte, eram enviados os “inimigos: membros das organizações 'fantoches' coloniais, agentes da polícia secreta portuguesa, sabotadores econômicos, 'operadores psicológicos', apologistas do capitalismo, defensores e praticantes de qualquer tipo de exploração do homem pelo homem, racistas, tribalistas, regionalistas, agentes do imperialismo, venais e corruptos (especialmente prostitutas), críticos da linha política da Frelimo, promotores de greves, da divisão do “lucro fácil'” (Serra citado em Moreira, 2010, p. 112) onde se procedia à "edificação de uma nova moral em catecismos inventados na hora" (Ba Ka Khosa, 2013, p. 65). 
Para a criação da nova sociedade, a Frelimo impôs uma política de "modernização autoritária" abrangente que pressupunha, entre outros, a criação de aldeias comunais, por oposição às povoações pequenas e dispersas, acentuando práticas impostas para a criação do "homem novo" como a negação das autoridades e culturas tradicionais, da religião, e a erradicação dos supostos marginais da sociedade como desempregados, ladrões, prostitutas, drogados, etc.

Neste sentido, visa o presente trabalho provocar uma reflexão sobre os factos ocorridos e recuperar memórias silenciadas dos campos de reeducação instituídos pelos dirigentes da Frelimo para construir/educar um "homem novo", a partir do confronto entre a obra de Ungulani Ba Ka Khosa e as publicações da imprensa moçambicana e internacional.

A metodologia usada é mista, quantitativa e qualitativa, fazendo recurso, em particular, à pesquisa documental, e à análise de conteúdo, enquanto ferramenta híbrida de recolha e tratamento de dados, técnica que permite obter informações relevantes sobre a temática aqui em análise, à luz daquilo que era publicado pelos jornais, locais e internacionais, e do texto do romance do historiador e escritor moçambicano Ungulani Ba Ka Khosa.

\section{ENTRE AS MEMÓRIAS SILENCIADAS}

Ungulani Ba Ka Khosa apresenta, em Entre as memórias silenciadas (2013), um retrato de Moçambique nos primeiros anos do período pós-independência com a ficção a desafiar e a recuperar as memórias silenciadas dos campos de reeducação instituídos pelos dirigentes da Frelimo para construir/educar um "Homem novo". Ba Ka Khosa inscreve a história do passado recente do país num texto que (re)visita um capítulo [obscuro] dos primeiros anos de liberdade que para os reeducandos foi sinónimo de violência, sofrimento, injustiças e exclusão da história e da memória. Como um dos autores mais provocadores da contemporaneidade moçambicana, Ba Ka Khosa combate a desmemória "dilui[ndo] o passado no presente, a ficção na realidade, fazendo da literatura um vivaz espaço para o debate político" (Gallo, 2013, p. 293).

Entre as memórias silenciadas, simplificando, apresenta a relação entre três prisioneiros de um campo de reeducação situado na província do Niassa e, em paralelo, a relação de quatro amigos que vivem em Maputo, retratando os universos rural e urbano no período pós-independência. Dos prisioneiros destaca-se Tomás, um camarada (ex-soldado da Frelimo) que lutou pela liberdade, respeitado, guardador de memórias, aquele que deixa a marca dos silenciados, dando dignidade aos mortos através de traços e desenhos nas paredes das casas que habitam nos campos:

pela dignidade que dá aos mortos, presenteando-os com traços que sempre renova quando a memória do tempo teima em apagá-los com a chuva e o vento a abaterem-se sobre as paredes. (...) é reconfortante ver o velho com os seus fios de algodão desgrenhados na cabeça e no queixo 
debruçado nas paredes dos defuntos, restaurando os sinais dos mortos.

(Ba Ka Khosa, 2013, p. 51)

Tomás personifica a injustiça, detido sem acusação e sem julgamento, resultado de um sistema mal-organizado, manchado por ilegalidades, abuso de poder e autoritarismo, sendo, como muitos outros reeducandos, vítima da falta de comunicação entre o governo de Maputo e os responsáveis pelos campos/centros de reeducação.

A ligação entre o espaço rural e o urbano faz-se através da ligação entre as personagens do campo de reeducação e as personagens associadas à cidade de Maputo.

Os reeducandos foram interna e forçosamente deslocados para os campos em zonais rurais longínquas dos locais de origem, sem acusação formada e sem se poderem defender e, por vezes, sem saberem a razão para a deslocação forçada. Nos campos eram assolados pela consciência da não identidade, situação explícita para os reeducandos, na obra de Ba Ka Khosa:

nós não éramos coisa alguma. Éramos nada. Não tínhamos nada. A nossa fronteira de existência estava entre a humanidade e a animalidade. De dia havia Homens à nossa guarda. À noite éramos entregues às regras da natureza. Estávamos na zona de ninguém. (...) Éramos pessoas sem o palco da existência a que chamam sociedade. (...) a nossa vida estava no limite. (2013, p. 59)

A afirmação de que o que se passa nos campos/centros de reeducação é assunto que não ficará registado na memória coletiva está explícito na obra:

amanhã ninguém se lembrará deste macabro gesto de nos atirarem para estes ermos espaços com a finalidade de criarem um homem novo. (...) Ninguém guardará na memória estes tempos falhados. (...) Somos número, carne de abate. Gente sem nome e sem registo. Não há história para nós. Não há memória. (...) Aqui não haverá registo, não haverá testemunhas. Este tempo será de sonho, de ficção. (...) Não haverá memória destes tempos. (Ba Ka Khosa, 2013, pp. 122-123)

Entre as memórias silenciadas (2013) retrata a desterritorialização forçada promovida pelo Estado da Frelimo através de deportações massivas para os campos de reeducação ou para os campos de trabalho longe da capital, em províncias longínquas como - Niassa, para limpar a sociedade, erguendo o homem novo livre do colonialismo e preparado para construir a nação. Terminada a operação dos centros de reeducação, passou-se a investir na construção de aldeias comunais - na obra é referida Unango (Ba Ka Khosa, 2013, p. 193) - como espaços adequados à nova realidade moçambicana onde os ex-reeducandos eram encorajados a se reunirem com as famílias e a reconstruir a vida, apoiando-se no coletivo. A integração em atividades produtivas a serem desenvolvidas coletivamente pela população contribuía para combater o subdesenvolvimento das províncias mais rurais e para recuperar indivíduos indisciplinados cujo comportamento teria sido prejudicial para a sociedade. 


\section{CORPUS JORNALÍsTICo}

O corpus selecionado para a análise empírica, a partir da análise de conteúdo, consistiu na literatura produzida pelos jornais moçambicanos da época e pelos jornais internacionais que também publicaram sobre o assunto, contabilizando-se um total de vinte e seis peças, distribuídas por diferentes géneros jornalísticos: breves, editoriais, artigos de opinião, reportagens, notícias, entrevistas, crónicas e outros. Os jornais considerados para análise foram: Notícias [Maputo]; Tempo [Maputo]; A Capital [Lisboa], com um trabaIho que remete para o Daily News da Tanzânia; Daily News [Dar es Salaam]; Afrique-Asie [Paris]; To the Point [Johannesburg]; Washington Post [Washington DC]; Los Angeles Times [Los Angeles]; Summary of World Broadcasts [London]; The Review [International Commission of Jurists] [Geneva].

O intervalo cronológico observado neste estudo respeita os anos que vão de 1976 até 1985 . No que se refere aos géneros jornalísticos presentes no corpus, verifica-se um predomínio do género reportagem logo seguido do género breves, sendo certo que há ainda a presença de um editorial, dois artigos de opinião, entre algumas notícias e uma entrevista. Registe-se que em alguns dos textos que compõem o corpus houve uma certa dificuldade em compreender a que género esses textos diziam respeito, dada a sua hibridez. Não raro, algumas reportagens eram intercetadas pela opinião pessoal do jornalista que as elaborava. Há que salientar que os textos nacionais se identificam com o discurso hegemónico do governo e passaram no crivo da censura.

Apresentado o corpus, procurar-se-á responder a alguns objetivos fundamentais neste trabalho: a) quais os temas recorrentes nas publicações jornalísticas moçambicanas; b) que género jornalístico ocorre com maior frequência nessas publicações; c) que diferenças existem entre os trabalhos realizados pela imprensa local e pela imprensa internacional, para que se possa fazer, a partir daí, as inferências e potenciais comparações com o trabalho desenvolvido pelo escritor Ungulani Ba Ka Khosa.

O presente estudo utiliza a análise de conteúdo como metodologia e técnica preferencial de recolha de dados. Crê-se assim que qualquer texto-objeto de qualquer estudo deve permitir a realização de inferências a partir de um corpus concreto.

Utilizando a análise de conteúdo como metodologia e técnica preferencial de recoIha de dados, escolheu-se como objeto de estudo "as publicações jornalísticas moçambicanas e estrangeiras sobre os campos de reeducação"; e uma vez delimitado o corpus, definiu-se aquilo que se pretendeu analisar no texto, preferindo-se uma abordagem aberta dos jornais, isto é, sem que se tenha formulado uma hipótese de partida. Depois disto, procurou-se recolher as principais temáticas referidas ao longo do corpus, para que estas se pudessem corporizar numa contagem posterior de frequências.

Depois de feita a categorização, procedeu-se à delimitação da unidade de registo, ou seja, da unidade base de significação que é inserida nas categorias e contabilizada posteriormente. A título de exemplo, em algumas ocasiões a unidade de registo selecionada terá sido, por exemplo, "referência à sociedade capitalista portuguesa", sendo que este termo albergava outras definições que se aproximariam desta, como por exemplo a "ideologia burguesa portuguesa". 
O presente estudo possui, por isso, três grandes categorias a reter: a) territorialidades; b) ideário do regime; c) e narrativas ideológicas. Cada uma destas categorias terá várias subcategorias e, algumas delas, dimensões positivas/negativas com base nas peças jornalísticas acedidas.

No que diz respeito à categoria n. ${ }^{\circ} 1$, aqui definida como "territorialidades", há uma prevalência, no corpus consultado, para a existência de três espaços geográficos em destaque: Portugal, Moçambique e Rússia.

No que diz respeito à categoria n. ${ }^{\circ}$ 2, "ideário do regime", importava descobrir de que forma era pontuada a subcategoria "campos de reeducação" vistos à luz dos média nacionais moçambicanos e internacionais, salientando-se duas dimensões dessa subcategoria: uma dimensão negativa associada à definição de campos de reeducação, descritos a partir de vários indicadores, como a questão das referências a tortura, ao desgaste físico, à menção direta da morte no campo, entre outras, e uma dimensão positiva, hasteada na forma como os jornalistas, editores, comentadores, teciam apreciações relevantes sobre o trabalho executado pela Frelimo, associando os campos de reeducação a aspetos que se relacionam com a política do homem novo, com as medidas de clemência, com a argumentação ligada à necessidade de punir os "vagabundos", os infratores, as prostitutas, os vadios e outros grupos marginalizados da sociedade moçambicana.

\begin{tabular}{lcc}
\hline $\begin{array}{c}\text { DESCRIÇÕES NEGATIVAS ASSOCIADAS } \\
\text { AOS CAMPOS DE REEDUCAÇÃo }\end{array}$ & FREQUÊNCIAS & $\begin{array}{c}\text { FREQUÊNCIA } \\
\text { RELATIVA }\end{array}$ \\
\hline Abuso e desgaste físico & 15 & $37,5 \%$ \\
\hline Dia-a-dia sofrível no campo & 12 & $30 \%$ \\
\hline Casos de tortura & 8 & $20 \%$ \\
\hline Más condições técnicas e estruturais do campo & 3 & $7,5 \%$ \\
\hline Mortes no campo & 2 & $5 \%$ \\
\hline N/Total & 40 & $100 \%$ \\
\hline
\end{tabular}

Tabela 1: Descrições negativas associadas aos campos de reeducação

Verifica-se que a imprensa enfatiza sempre os temas e as descrições que se associam ao desgaste dos prisioneiros, sem que assim os defina muitas vezes, particularmente no caso dos média moçambicanos.

É sem surpresa que se verifica uma prevalência dos argumentos que fazem associar os campos de reeducação ao combate a uma série de problemas da sociedade moçambicana, definidos em termos de grupos marginais, prostituição, vida ociosa.

No que se refere à categoria n. ${ }^{\circ}$, definida como "narrativas ideológicas", verifica-se a presença das subcategorias de socialismo, marxismo e leninismo e capitalismo. No que se refere à comparação entre as subcategorias propostas, há uma diferença notória entre as frequências atribuídas ao socialismo $(\mathrm{N}=5)$ e ao capitalismo $(\mathrm{N}=20)$ que os jornais atribuem a Portugal. 


\begin{tabular}{llc}
\hline \multicolumn{1}{c}{$\begin{array}{c}\text { DESCRIÇÕES POSITIVAS ASSOCIADAS } \\
\text { AOS CAMPOS DE REEDUCAÇÃo }\end{array}$} & FREQUÊNCIAS & $\begin{array}{c}\text { FREQUÊNCIA } \\
\text { RELATIVA }\end{array}$ \\
\hline $\begin{array}{l}\text { Combate aos marginalizados, prostituição, vagabundos, } \\
\text { vadios, ladrões e dissidentes políticos }\end{array}$ & 40 & $57,14 \%$ \\
\hline Reforço positivo da política do homem novo & 12 & $17,1 \%$ \\
\hline Exaltação da política de clemência & 7 & $10 \%$ \\
\hline Referência direta positiva sobre os campos de reeducação & 4 & $5,71 \%$ \\
\hline Argumentação apoiada na luta contra o subdesenvolvimento & 3 & $4,28 \%$ \\
\hline Exaltação dos grupos dinamizadores & 2 & $2,85 \%$ \\
\hline Referência à entrega de dinheiro e de alfaias para reconstrução & 2 & $100 \%$ \\
\hline N/Total & 70 & $2,85 \%$ \\
\hline
\end{tabular}

Tabela 2: Descrições positivas associadas aos campos de reeducação

Para além dessa questão, importa frisar que no que se refere às suas dimensões, positiva e negativa, ao capitalismo raramente é atribuído um sentido positivo.

Se se atentar agora às opções temáticas provenientes do corpus, verificar-se-á uma preferência pelos temas associados às dimensões positivas/negativas dos campos de educação, bem como às diferenças que existem entre a imprensa moçambicana e a imprensa internacional.

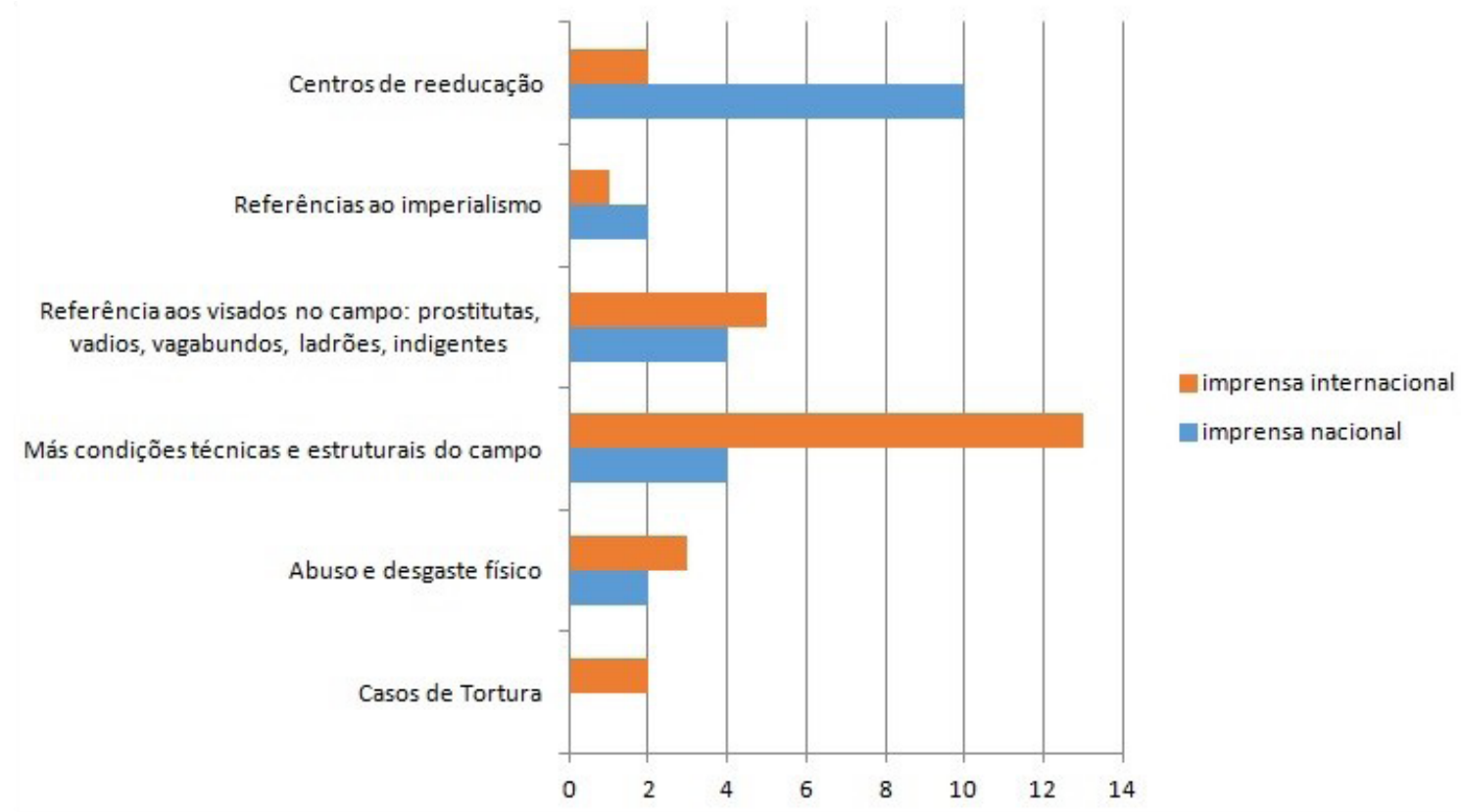

Gráfico 1: Comparação entre os temas mais comuns na imprensa moçambicana e na imprensa internacional 
No que respeita aos campos temáticos explorados, verifica-se então que enquanto a imprensa moçambicana explica os temas relativos aos centros de reeducação, vislumbrados de forma positiva, engrandecendo o ideário da Frelimo, nas suas múltiplas derivações, a imprensa internacional salienta, de forma expressiva, as más condições técnicas e estruturais dos campos de reeducação. Há também um outro item em que a imprensa internacional salienta uma diferença para com a imprensa moçambicana: as referências aos visados no campo: as prostitutas, os indigentes, entre outras definições.

\section{Conclusão}

Nos artigos do jornal Notícias ${ }^{1}$ de Maputo e da Revista Tempo² é visível o discurso hegemónico do governo ainda que se questione os objetivos dos campos; os artigos dos média internacionais [A Capital com um artigo que remete para o Daily News da Tanzánia; o Daily News; Afrique-Asie; To the Point; Washington Post; Los Angeles Times; Summary of World Broadcasts, The Review [International Commission of Jurists] oferecem uma leitura que chama à atenção para a injustiça e violação de direitos humanos. O discurso jornalístico nacional sofre alterações, especialmente a partir das visitas de Samora Machel ao Niassa e a Cabo Delgado em 1981, passando a incorporar informação sobre irregularidades no processo de reeducação. Esta mudança deveu-se à "pressão da opinião pública internacional", tendo o presidente ordenado "inquéritos confidenciais sobre as condições de vida nos campos" (Pinto de Sá, 1995, p. 26).

Os textos aqui analisados mostram que "a pátria [moçambicana] ergueu-se com as vozes dos que vieram das matas. (...) Eles é que ditaram as regras. Soterraram tudo e todos os que quiseram clamar por vozes plurais" (Ba Ka Khosa, 2013, p. 101); o corpus jornalístico aqui analisado e o romance Entre as memórias silenciadas (2013) de Ungulani $\mathrm{Ba} \mathrm{Ka}$ Khosa complementam-se, retratando a intransigência revolucionária da Frelimo na primeira década pós-independência, alertando para a necessidade de combater a desmemória e recuperar vozes silenciadas, contribuindo para construir um capítulo da história de Moçambique a várias vozes.

\section{REFERÊNCIAS}

Ba Ka Khosa, U. (2013). Entre as memórias silenciadas. Maputo: Alcance Editores.

\footnotetext{
' O Notícias é um jornal diário publicado em Maputo, Moçambique, fundado por Manuel Simões Vaz a 15 de abril de 1926, tendo sucedido a O Correio de Moçambique (Hohlfeldt, 2010, p.3).

${ }^{2}$ A revista Tempo foi fundada em 1970 por jornalistas próximos da Frente de Libertação de Moçambique. “Após a independência de Moçambique, a nova política de informação confiou aos meios de comunicação, em especial à revista Tempo, o compromisso de apoiar a emancipação feminina, devendo publicar notícias do "interesse das mulheres", além de noticiar atividades da Organização das Mulheres de Moçambique (OMM). Apesar do discurso hegemónico do governo e da censura exercida em suas edições, a defesa pela liberdade de imprensa tornou essa revista um campo de brechas, com discursos contraditórios e críticos àqueles do governo no período" (Santana, 2009, p. 83). Para mais informação sobre a revista Tempo, consultar Machaiana (2002).
} 
Gallo, F. (2015). Resenha. BA KA KHOSA, Ungulani. Entre memórias silenciadas. Maputo, Moçambique. Ed. Alcance, 2013. 226p. SCRIPTA, 19(37), 293-295. Retirado de https://dialnet.unirioja.es/descarga/ articulo/5821945.pdf

Hohlfeldt, A. (2010). Os profissionais de Moçambique no campojornalístico em 1960: consensos e contradições. Grupo de Trabalho de Jornalismo do XVIII Encontro da Compôs, na PUCMG, Belo Horizonte, MG, em junho de 2010. Retirado de http://compos.com.puc-rio.br/media/gt9_antonio_ hohfeldt.pdf

Machiana, E. (2002). A revista Tempo e a Revolução Moçambicana: da mobilização popular ao problema da crítica na informação, 1974-1977. Maputo: Promédia.

Moreira, T. T. (2010). Memória e história em Campos de trânsito de João Paulo Borges Coelho. Afro- Ásia, 42, 109-124. Retirado de ttps://www.redalyc.org/articulo.oa?id=77020008004

Pinto de Sá, J. (1995, 25 de junho). Os campos da vergonha. A história inédita dos "centros de reeducação" em Moçambique. Público Magazine, 277, 18-34. Retirado de http://macua.blogs.com/files/ magazine1995camposfrelimo.pdf

Santana, J. S. (2009). Mulheres de Moçambique na revista Tempo: o debate sobre o lobolo (casamento). Revista de História, 1(2), 82-98. Retirado de http://www.revistahistoria.ufba.br/2009_2/ao6.pdf

Thomaz, O. R. (2008). "Escravos sem dono": a experiência social dos campos de trabalho em Moçambique no período socialista. Revista de Antropologia, 51(1), 177-214. Retirado de https://www.revistas.usp.br/ra/ article/view/27305

\section{NOTAS BIOGRÁFICAS}

Orquídea Moreira Ribeiro é doutorada em Ciências Humanas e Sociais, com especialização em Cultura, com uma tese em Estudos Afro-Americanos; é professora auxiliar no Departamento de Letras, Artes e Comunicação da Universidade de Trás-os-Montes e Alto Douro (UTAD), onde leciona unidades curriculares na área das Ciências da Cultura, como Teorias da Cultura, Culturas Pós-Coloniais da Língua Portuguesa e Culturas Africanas Comparadas. É investigadora integrada no Centro de Investigação Transdisciplinar "Cultura, Espaço e Memória" (CITCEM) da Faculdade de Letras da Universidade do Porto (FLUP) onde participa no Grupo de Pesquisa "Representações Locais e Globais" / Representações Glocais". A sua principal área de investigação centra-se nas Culturas Africanas de Língua Portuguesa e Culturas Comparadas, tendo publicado vários artigos em estudos africanos e afro-americanos.

Email: oribeiro@utad.pt

Morada: Departamento de Letras, Artes e Comunicação, Universidade de Trás-os-Montes e Alto Douro (UTAD), Quinta de Prados, Apartado 1013, 5000-801 Vila Real

Daniela Esperança Monteiro da Fonseca nasceu em 1977 e ingressou no ensino superior em 1995, na Universidade do Minho, em Braga, licenciando-se em Comunicação Social, no ano de 2000. Em 2001 entrou no mestrado em Ciências da Comunicação-ramo Informação e Jornalismo, na mesma universidade, defendendo a sua tese intitulada "A evolução do género jornalístico" em 2004. Em termos profissionais fez assessoria 
de imprensa no Sindicato dos Trabalhadores em Funções Públicas e Sociais do Norte (STFPSN) no Porto, entre 2005 e 2007. Doutorou-se em Ciências da Comunicação, em 2014, na Universidade da Beira Interior, Covilhã, com uma tese intitulada "O papel das Relações Públicas na modernização dos sindicatos portugueses. Novos e velhos movimentos sociais". É Professora Auxiliar na Universidade de Trás-os-Montes e Alto Douro, onde ingressou em setembro de 2007. É diretora da licenciatura e do mestrado em Ciências da Comunicação e vice-diretora do curso de Comunicação e Multimédia, desde 2017.

Email: dfonseca@utad.pt

Morada: Departamento de Letras, Artes e Comunicação, Universidade de Trás-os-Montes e Alto Douro (UTAD), Quinta de Prados, Apartado 1013, 5000-801 Vila Real

* Submetido: 12-09-2018

$*$ Aceite: 02-02-2019 